\title{
Saliva as the Stress Biomarker after Fasting Exposure on Adult Girls and Boys
}

\author{
Arpana Devi ${ }^{1}$, Kriti Sharma ${ }^{1}$, Arup Giri ${ }^{1,2 *}$
}

\begin{abstract}
This experiment was conducted to determine the fasting effects on anthropometric parameters and salivary antioxidant properties in girls and boys. Saliva samples were collected from 18 healthy girls (control -9 and fasting -9 girls) and 12 healthy boys (control -6 and fasting -6 boys). Saliva was collected 4 times from all the subjects at a time interval of $2 \mathrm{~h}$. For anthropometric parameters, body weight, body temperature, pulse rate (PR), systolic blood pressure (SBP), and diastolic blood pressure (DBP) were measured during each saliva collection time. Antioxidant parameters of all the saliva samples were evaluated. Most of the anthropometric parameters such as temperature, PR, SBP, and DBP of the fasting group were significantly $(P<0.5)$ decreases than the control group of both boy's and girl's in the different time intervals. Antioxidant properties were significantly $(P<0.5)$ higher in the fasting group of girls, but the insignificantly different levels were found in the boy's group. This study was indicating that fasting affected the anthropometric parameters (PR, SBP, and DBP), mainly in the girls. Salivary antioxidant properties were mostly lower in the girls' fasting group. Therefore, saliva may be a useful stress biomarker during fasting conditions.

Keywords: Antioxidant, 2,2-Diphenyl-1-picrylhydrazyl, Ferric reducing ability of plasma, Fasting, Saliva

Asian Pac. J. Health Sci., (2020); DOI: 10.21276/apjhs.2020.7.3.12
\end{abstract}

\section{INTRODUCTION}

Saliva is a secreted watery substance (98\%) produced by the salivary glands of animals, including humans. About $0.5-1.5 \mathrm{l} /$ day saliva secreted in humans. Saliva contains lots of essential substances, such as electrolytes, mucus, antibacterial agents, epithelial cells, and many enzymes. ${ }^{[1,2]}$ Saliva has been used for the diagnosis of the disease since ancient times. ${ }^{[3]}$ Furthermore, saliva serves as an outstanding biomarker for another oral associated disease such as periodontal inflammation, oral squamous cell carcinoma, salivary gland tumors, and pancreatic cancer. ${ }^{\left[{ }^{[-7]}\right.}$ The antioxidant properties of saliva have been found to have decreased in patients with periodontal disease. ${ }^{[8]}$ However, studies indicated that in Ramadan's fasting condition, the rate of saliva secretion decreased, changed in saliva composition, etc. ${ }^{[9]}$

In addition, intermittent fasting has been found to play a critical role in health. ${ }^{[10]}$ Fasting helps alleviate hypertension and cardiovascular disease..$^{[1,12]}$ No studies have yet been carried out to determine the role of human salivary antioxidants and changes in anthropometric parameters in a short fasting period. Hence, this study was intended to evaluate the effect of fasting in boys and girls on physiology and salivary antioxidant properties.

\section{Materials and Methods}

\section{Ethical Clearance}

During this time of research, religious fasting was continued. Therefore, there was no need for expert committee clearance to carry out this study. However, all individuals have voluntarily participated in this experiment with their full consent. They were a postgraduate student at this university. Previously, they were aware of the method of collecting saliva. They were also aware of the normal level of all anthropometric parameters.

\section{Study Site and Experimental Design}

This study was conducted at Arni University Campus, Himachal Pradesh, India, in 2019. This has chosen boys and girls who have
'Department of Life Science, School of Basic Sciences, Arni University, Kangra, Himachal Pradesh, India

${ }^{2}$ Animal Biotechnology Laboratory, DRDO-Defence Institute of High Altitude Research, Chandigarh, India

Corresponding Author: Dr. Arup Giri, Arni University, ICMRSenior Research Fellow, Animal Biotechnology Laboratory, DRDODefence Institute of High Altitude Research, Chandigarh, India. Tel.: +91-9646919386. E-mail: arupsatadal@gmail.com

How to cite this article: Devi A, Sharma K, Giri A. Saliva as the Stress Biomarker after Fasting Exposure on Adult Girls and Boys. Asian Pac. J. Health Sci., 2020; 7(3):47-52

Source of support: Nil

Conflicts of interest: None

Received: 10/05/2020 Revised: 22/06/2020 Accepted: 08/07/2020

no record of metabolic conditions such as thyroid dysfunction, cardiovascular disease, diabetes, eating disorders, and an inflammatory disorder. For one consecutive series, all the participants were created. The girls' average age was within 20 years, and the average weight was within $50 \mathrm{~kg}$, while the boys' average age was 25 years, and the average weight was within 58.1 kilograms. Samples of saliva were obtained from 18 healthy girls (control -9 and fasting -9 ) and 12 healthy boys (control -6 and fasting -6 ). Both were granted ad libitum drinking water, but they drunk before $1 \mathrm{~h}$ of collecting saliva samples. Not all of the volunteers had done some other workout, so they did not wander. At a time span of $2 \mathrm{~h}(10 \mathrm{am}, 12 \mathrm{pm}, 2 \mathrm{pm}$, and 4 pm), saliva was obtained from all the subjects 4 times.

\section{Prototypical STARD Diagram to Report the Flow of Girls and Boys Participants through the Study}

\section{Measurement of anthropometric parameters}

All the subjects were measured in height using a measuring tape. Bodyweight was measured using a weight balance machine. The temperature was measured using a digital electronic thermometer

O2020 The Author(s). This is an open access article distributed under the terms of the Creative Commons Attribution License (http:// creativecommons.org/ licenses/by/4.0/), which permits unrestricted use, distribution, and reproduction in any medium, provided the original work is properly cited. 
with a heat sensor. Blood pressure (BP) meter (Omron automatic BP monitor NANZ A-31) was used to measure all subjects' BP. The pulse rate (PR) was calculated when the $B P$ was measured by the BP meter (NANZ A-31).

\section{Saliva Collection}

The saliva was collected in the sample collection tube by the spitting method. The saliva collection started at 10 am and ended at $4 \mathrm{pm}$. The time interval for the collection of saliva was $2 \mathrm{~h}$. After the saliva was collected, the entire sample was stored in a deep freeze $\left(-80^{\circ} \mathrm{C}\right)$ until the antioxidant parameters were analyzed.

\section{Analysis of Antioxidant Parameters}

2,2-Diphenyl-1-picrylhydrazyl (DPPH) ${ }^{[13]}$ and ferric reducing ability of plasma (FRAP) ${ }^{[14]}$ were performed for antioxidant parameter analysis. The whole test was performed in a triplicate test series. All participants had a discussion class about these methods and the use of all these methods.

\section{Statistical Analysis}

We selected 18 girls (nine in each group) and 12 boys (six in each group). We did so in accordance with the standard statistical method to select a minimum of six experimental subjects. Statistical analysis was performed using version 22.0 of the SPSS. All datasets have been executed for the $t$-test. ANOVA was performed to determine the level of significance between the different time intervals of two groups.

\section{Results}

\section{Anthropometric Parameters}

No adverse events occurred during the measurement of anthropometric parameters and saliva spitting at different

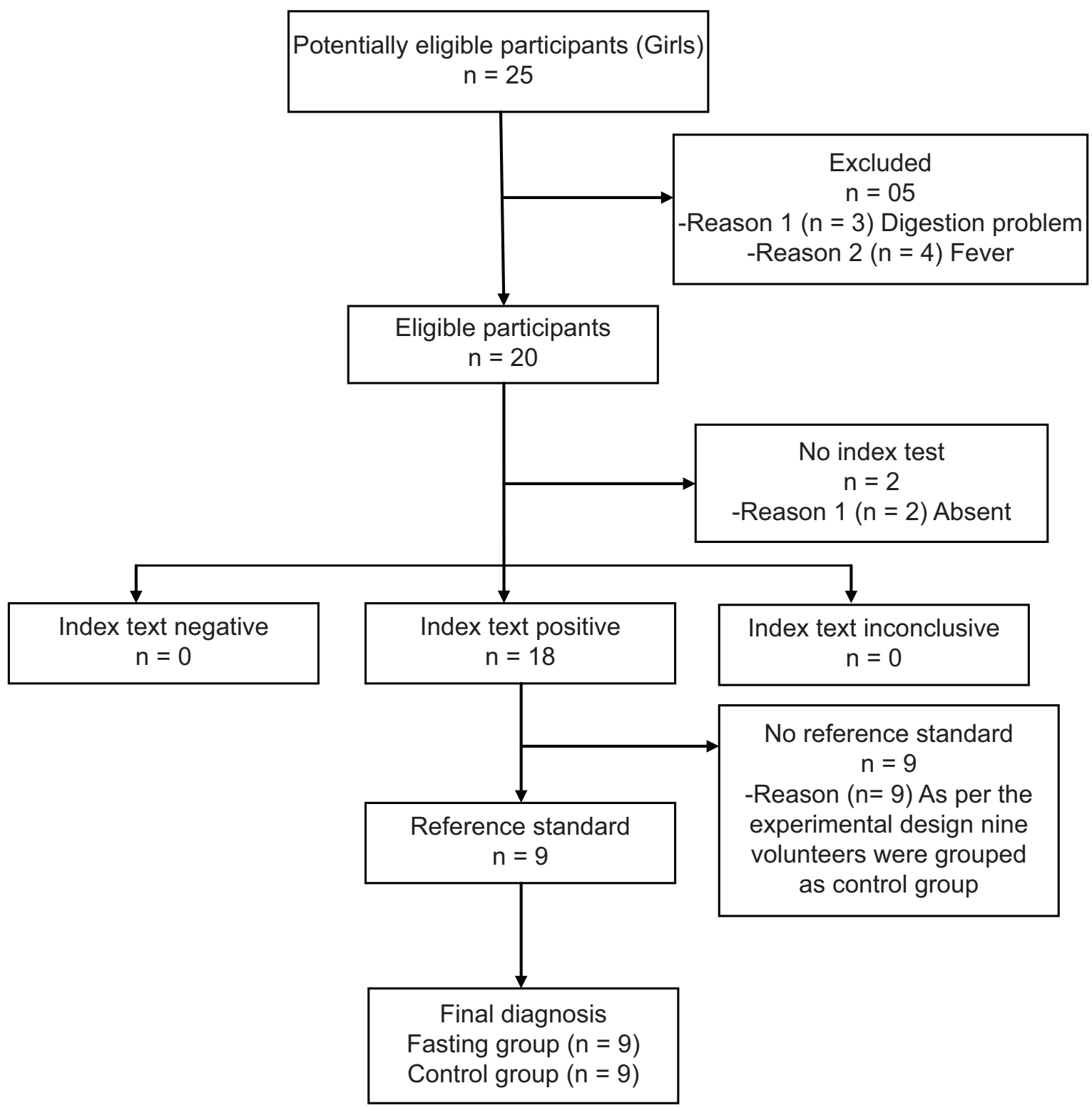




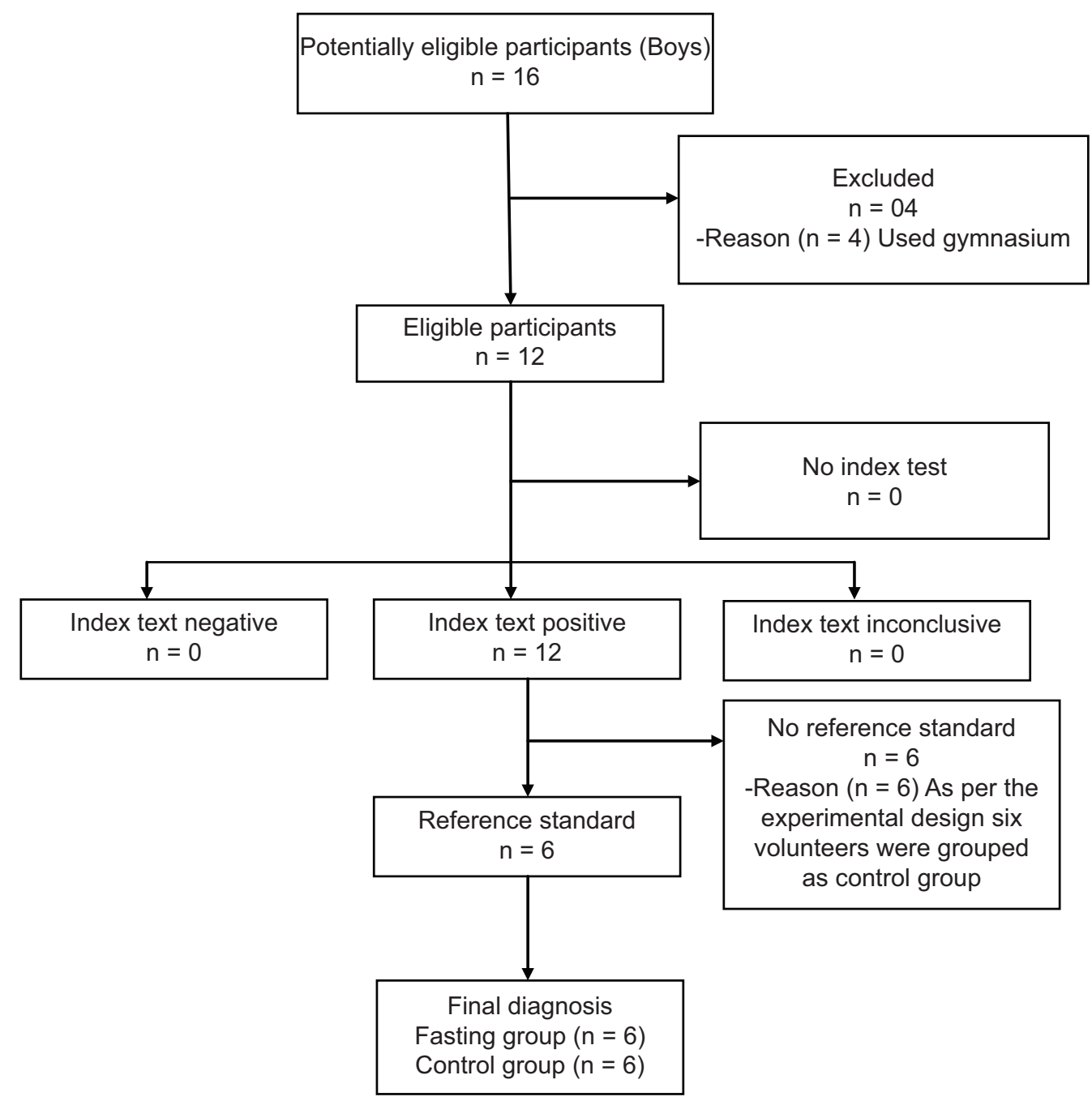

times of both sexes. There is no significant variation in the bodyweight of girls and boys between control and fasting groups at different periods [Table 1]. The temperature in fasting boys and girls increased significantly $(P<0.5)$ [Table 2]. The PR in boys showed a significant decrease $(P<0.5)$ between control and fasting communities at all times. Whereas in the girls' fasting group, the PR decreased significantly at $12 \mathrm{pm}$ and 4 $\mathrm{pm}$. There was no significant difference between the different time ranges in the control and fasting categories for both boys and girls [Table 2]. In boys and girls, systolic BP (SBP) showed a significant $(P<0.5)$ difference (decreased pattern) at different time intervals within the fasting community. The girls' fasting group showed only a significant reduction in the pattern of diastolic BP (DBP) [Table 2].

\section{Antioxidant Parameters}

The result of the FRAP level after the $t$-test in girls showed a significant increase in the fasting group level $(P<0.5)$ at 10 am, $12 \mathrm{pm}$, and $2 \mathrm{pm}$ but with the exception of $4 \mathrm{pm}$. In the case of boys, the FRAP level increased significantly, except at $12 \mathrm{pm}$. A significant decreasing pattern of FRAP levels has been identified in the fasting group of both sexes [Table 3]. Both the fasting groups of girls and boys showed a significant decline in DPPH levels in the fasting group. It has also been found that the DPPH level has increased at different times in both sexes [Table 3].

\section{Discussion}

\section{Anthropometric Parameters}

BWs findings showed no significant improvement in both sexes. The result is consistent with the analysis that no significant differences were recorded in BW. ${ }^{[15,16]}$ Our findings also suggest that the reduction of body weight in fasting conditions requires a minimum of $48 \mathrm{~h} \cdot{ }^{[17]}$ The trend in body temperature decreased significantly during a different time period, primarily in the fasting community. This may be due to the effect of fasting on the fasting community of counteracting the amount of body energy. ${ }^{[18]}$

Furthermore, due to the fasting state, this can be attributed to the lower metabolic rate in the body. Lower metabolic processes are expected to reduce the lower secretion of thyroid hormone, which is the primary hormone for body temperature regulation after the body's basal metabolic rate increases or decreases. ${ }^{[19]}$ Another effect may be a decrease in glucose use and, 
Table 1: Body weight of girls and boys in control and fasting conditions at a different time intervals

\begin{tabular}{llcc}
\hline Group & Time & Control & Fasting \\
\hline Boys & $10 \mathrm{am}$ & $52.39 \pm 1.73^{\mathrm{a}}$ & $52.30 \pm 2.02^{\mathrm{a}}$ \\
& $12 \mathrm{pm}$ & $52.39 \pm 1.73^{\mathrm{a}}$ & $52.30 \pm 2.02^{\mathrm{a}}$ \\
& $2 \mathrm{pm}$ & $52.39 \pm 1.73^{\mathrm{a}}$ & $52.30 \pm 2.02^{\mathrm{a}}$ \\
\multirow{4}{*}{ Girls } & $4 \mathrm{pm}$ & $52.39 \pm 1.73^{\mathrm{a}}$ & $52.30 \pm 2.02^{\mathrm{a}}$ \\
& $10 \mathrm{am}$ & $57.97 \pm 4.67^{\mathrm{a}}$ & $58.33 \pm 4.19^{\mathrm{a}}$ \\
& $12 \mathrm{pm}$ & $54.97 \pm 4.67^{\mathrm{a}}$ & $58.33 \pm 4.19^{\mathrm{a}}$ \\
& $2 \mathrm{pm}$ & $54.97 \pm 4.67^{\mathrm{a}}$ & $58.33 \pm 4.19^{\mathrm{a}}$ \\
& $4 \mathrm{pm}$ & $54.97 \pm 4.67^{\mathrm{a}}$ & $58.33 \pm 4.19^{\mathrm{a}}$ \\
\hline
\end{tabular}

Table 2: Difference of anthropometric parameters in control and fasting group of both sexes during the different time intervals

\begin{tabular}{|c|c|c|c|c|}
\hline Parameter & Group & Time & Control & Fasting \\
\hline \multirow[t]{8}{*}{ Temperature } & \multirow[t]{4}{*}{ Boys } & $10 \mathrm{am}$ & $97.17 \pm 0.21^{\mathrm{a}}$ & $97.15 \pm 0.24^{a}$ \\
\hline & & $12 \mathrm{pm}$ & $96.92 \pm 0.47^{a}$ & $96.98 \pm 0.34^{a}$ \\
\hline & & $2 \mathrm{pm}$ & $96.35 \pm 1.14^{\mathrm{a}}$ & $96.95 \pm 0.33^{\mathrm{a}}$ \\
\hline & & $4 \mathrm{pm}$ & $97.38 \pm 0.76^{\mathrm{a}}$ & $97.52 \pm 0.34^{\mathrm{a}}$ \\
\hline & \multirow[t]{4}{*}{ Girls } & $10 \mathrm{am}$ & $96.67 \pm 0.42^{\mathrm{a}}$ & $97.02 \pm 0.34^{\mathrm{a}}$ \\
\hline & & $12 \mathrm{pm}$ & $96.82 \pm 0.63^{\mathrm{a}}$ & $96.28 \pm 0.46^{\mathrm{a}}$ \\
\hline & & $2 \mathrm{pm}$ & $96.33 \pm 0.47^{a}$ & $96.72 \pm 0.56^{\mathrm{a}}$ \\
\hline & & $4 \mathrm{pm}$ & $96.44 \pm 0.52^{\mathrm{a}}$ & $96.01 \pm 0.54^{\mathrm{a}}$ \\
\hline \multirow[t]{8}{*}{ Pulse rate } & \multirow[t]{4}{*}{ Boys } & $10 \mathrm{am}$ & $79.50 \pm 4.51^{\mathrm{a}}$ & $68.83 \pm 4.09^{\mathrm{a} *}$ \\
\hline & & $12 \mathrm{pm}$ & $75.17 \pm 3.91^{\mathrm{a}}$ & $69.00 \pm 3.33^{\mathrm{a} *}$ \\
\hline & & $2 \mathrm{pm}$ & $77.17 \pm 3.83^{\mathrm{a}}$ & $68.00 \pm 3.37^{a *}$ \\
\hline & & $4 \mathrm{pm}$ & $87.00 \pm 6.89^{\mathrm{a}}$ & $74.89 \pm 4.89^{\mathrm{b} *}$ \\
\hline & \multirow[t]{4}{*}{ Girls } & $10 \mathrm{am}$ & $83.89 \pm 11.47^{a}$ & $84.22 \pm 5.46^{\mathrm{a}}$ \\
\hline & & $12 \mathrm{pm}$ & $94.44 \pm 3.69^{a}$ & $81.78 \pm 5.52^{\mathrm{a}}$ \\
\hline & & $2 \mathrm{pm}$ & $87.44 \pm 6.37^{a}$ & $84.11 \pm 5.25^{a}$ \\
\hline & & $4 \mathrm{pm}$ & $96.89 \pm 3.81^{\mathrm{a}}$ & $82.44 \pm 3.81^{\mathrm{a}}$ \\
\hline \multirow{8}{*}{$\begin{array}{l}\text { Systolic blood } \\
\text { pressure }\end{array}$} & \multirow[t]{4}{*}{ Boys } & $10 \mathrm{am}$ & $119.33 \pm 3.43^{a}$ & $129.17 \pm 6.76^{\mathrm{b} *}$ \\
\hline & & $12 \mathrm{pm}$ & $120.33 \pm 4.33^{\mathrm{a}}$ & $110.67 \pm 10.27^{a}$ \\
\hline & & $2 \mathrm{pm}$ & $120.33 \pm 4.33^{a}$ & $116.33 \pm 3.35^{\mathrm{a}}$ \\
\hline & & $4 \mathrm{pm}$ & $119.17 \pm 3.17^{a}$ & $121.83 \pm 8.98^{\mathrm{ab}}$ \\
\hline & \multirow[t]{4}{*}{ Girls } & $10 \mathrm{am}$ & $109.33 \pm 3.84^{a}$ & $101.33 \pm 3.04^{\mathrm{a} *}$ \\
\hline & & $12 \mathrm{pm}$ & $100.56 \pm 3.4^{\mathrm{a}}$ & $101.67 \pm 3.67^{\mathrm{a}}$ \\
\hline & & $2 \mathrm{pm}$ & $104.00 \pm 4.34^{\mathrm{a}}$ & $93.78 \pm 3.01^{a *}$ \\
\hline & & $4 \mathrm{pm}$ & $109.33 \pm 4.26^{a}$ & $95.67 \pm 4.01^{\mathrm{a} *}$ \\
\hline \multirow{8}{*}{$\begin{array}{l}\text { Diastolic blood } \\
\text { pressure }\end{array}$} & \multirow[t]{4}{*}{ Boys } & $10 \mathrm{am}$ & $80.67 \pm 3.01^{\mathrm{a}}$ & $76.83 \pm 3.28^{\mathrm{a}}$ \\
\hline & & $12 \mathrm{pm}$ & $72.00 \pm 3.86^{\mathrm{a}}$ & $71.50 \pm 4.16^{\mathrm{a}}$ \\
\hline & & $2 \mathrm{pm}$ & $72.00 \pm 3.86^{\mathrm{a}}$ & $67.33 \pm 2.64^{a}$ \\
\hline & & 4 pm & $77.67 \pm 3.54^{\mathrm{a}}$ & $71.17 \pm 4.71^{\mathrm{a}}$ \\
\hline & \multirow[t]{4}{*}{ Girls } & $10 \mathrm{am}$ & $77.11 \pm 3.12^{\mathrm{a}}$ & $72.00 \pm 2.48^{\mathrm{b} *}$ \\
\hline & & $12 \mathrm{pm}$ & $73.00 \pm 2.36^{\mathrm{a}}$ & $68.00 \pm 1.95^{\mathrm{ab}}$ \\
\hline & & $2 \mathrm{pm}$ & $73.11 \pm 3.09^{\mathrm{a}}$ & $63.22 \pm 2.27^{\mathrm{a}}$ \\
\hline & & $4 \mathrm{pm}$ & $76.44 \pm 3.21^{\mathrm{a}}$ & $63.56 \pm 3.89^{\mathrm{a} *}$ \\
\hline
\end{tabular}

Means bearing the different superscripts $(a, a b, b)$ in a column differ significantly $(P<0.05) .{ }^{*}$ Signifies the difference in a row $(P<0.05)$

in the meantime, a decrease in blood flow as well as a decrease in multiorgan metabolism. ${ }^{[20,21]}$

The SBP standard value is $120 \mathrm{mmHg}$. However, DBP is the minimum pressure exerted by the left ventricle in the aorta during cardiac relaxation for blood discharge to the aorta. ${ }^{[18]}$ Both SBP and DBP were reduced in a different time interval in the fasting group, as were SBP and DBP reduced in the fasting group, especially in the girls. This may be due to changes in the functioning of the sympathetic nervous system during the fasting period, especially in girls. ${ }^{[16,22,23]}$

Reduced sympathetic vasoconstrictor function due to higher norepinephrine secretion, brain-derived neurotrophic factor, and higher insulin levels is most responsible for lowering acute BP in fasting conditions. ${ }^{[12,24]}$
Table 3: Difference of FRAP, DPPH, and ABTS level in control and fasting group

\begin{tabular}{llccc}
\hline Parameter & Group & Time & Control & Fasting \\
\hline FRAP & Boys & $10 \mathrm{am}$ & $1.11 \pm 0.37^{\mathrm{a}}$ & $1.39 \pm 0.31^{\mathrm{b} *}$ \\
& & $12 \mathrm{pm}$ & $1.09 \pm 0.37^{\mathrm{a}}$ & $1.00 \pm 0.31^{\mathrm{a}}$ \\
& $2 \mathrm{pm}$ & $1.03 \pm 0.37^{\mathrm{a}}$ & $1.30 \pm 0.31^{\mathrm{ab} *}$ \\
& $4 \mathrm{pm}$ & $1.01 \pm 0.34^{\mathrm{a}}$ & $1.17 \pm 0.34^{\mathrm{a} *}$ \\
& Girls & $10 \mathrm{am}$ & $0.89 \pm 0.27^{\mathrm{a}}$ & $1.14 \pm 0.28^{\mathrm{b} *}$ \\
& $12 \mathrm{pm}$ & $0.91 \pm 0.27^{\mathrm{a}}$ & $1.07 \pm 0.23^{\mathrm{b} *}$ \\
& $2 \mathrm{pm}$ & $0.91 \pm 0.24^{\mathrm{a}}$ & $1.15 \pm 0.26^{\mathrm{b} *}$ \\
& $4 \mathrm{pm}$ & $1.03 \pm 0.25^{\mathrm{a}}$ & $0.28 \pm 0.03^{\mathrm{a} *}$ \\
DPPH & $10 \mathrm{am}$ & $49.92 \pm 21.98^{\mathrm{a}}$ & $49.97 \pm 21.93^{\mathrm{b}}$ \\
& \multirow{4}{*}{ Boys } & $12 \mathrm{pm}$ & $49.92 \pm 21.87^{\mathrm{a}}$ & $49.90 \pm 21.85^{\mathrm{b}}$ \\
& & $2 \mathrm{pm}$ & $46.62 \pm 1.97^{\mathrm{a}}$ & $23.27 \pm 1.83^{\mathrm{a}^{*}}$ \\
& & $4 \mathrm{pm}$ & $44.67 \pm 1.95^{\mathrm{a}}$ & $21.45 \pm 4.50^{\mathrm{a}^{*}}$ \\
& \multirow{4}{*}{ Girls } & $10 \mathrm{am}$ & $24.21 \pm 1.55^{\mathrm{a}}$ & $35.85 \pm 5.89^{\mathrm{b}^{*}}$ \\
& & $12 \mathrm{pm}$ & $22.17 \pm 1.01^{\mathrm{a}}$ & $24.99 \pm 1.54^{\mathrm{a}^{*}}$ \\
& $2 \mathrm{pm}$ & $24.18 \pm 1.56^{\mathrm{a}}$ & $25.11 \pm 1.55^{\mathrm{a}}$ \\
& & $4 \mathrm{pm}$ & $25.19 \pm 1.54^{\mathrm{a}}$ & $25.19 \pm 1.54^{\mathrm{a}}$ \\
\hline
\end{tabular}

Means bearing the different superscripts $(a, a b, b)$ in a column differ significantly $(P<0.05)$ and ${ }^{*}$ signifies the difference in a row $(P<0.05)$. FRAP: Ferric reducing ability of plasma, DPPH: 2,2-Diphenyl-1-picrylhydrazyl, ABTS: 2,2'-Azinobis(3-ethylbenzothiazoline-6-sulfonic acid

\section{Antioxidant Parameters}

Fasting induces activation of lipid burning in the body and decreases the metabolic rate of rest at the optimum concentration of oxygen. ${ }^{[16,25]}$ Animals must reduce the metabolic rate in response to a long period of fasting. This change in metabolic status may be associated with higher levels of oxidative stress. ${ }^{[26]}$ Earlier studies showed an increase in salivary alpha-amylase levels during exercise. ${ }^{[27]}$ Dental caries caused oxidative stress to the oral cavity. Salivary antioxidants were higher during dental caries. ${ }^{[28,29]}$ Another study reported cigarette smoking and exercise in the oral cavity-induced oxidative stress and increased the antioxidant capacity of the saliva. ${ }^{[30]}$ Total antioxidant capacity and uric acid saliva have also been reported to have changed during occupational exposure to mining dust. ${ }^{[31]}$ This may be because the oxidative stress in the oral cavity is attenuated. Thus, the salivary antioxidant properties have been modified under various stressful conditions. In our study, it was found that the levels of antioxidant parameters in the fasting group were significantly lower than those in the control group of both sexes. As a result, this finding suggested a decrease in salivary antioxidant capacity for extended fasting in both sexes. ${ }^{[32,33]}$ It may be due to the fasting stress that affects the salivary properties of antioxidants. However, at the initial stage of the experiment, antioxidant power was higher for both sexes in the fasting group. This happened because all the people were well used to having breakfast in the morning. Due to the fasting stress, the antioxidant properties have been triggered to fight stress in the body. The antioxidant strength in the fasting girl community was slightly lower at the final stage of the experiment. Fasting was also mainly influenced by the salivary properties of girls. Earlier research has shown that the salivary properties differed between the sexes. ${ }^{[28]}$ In the category of girls, anthropometric parameters have often been changed. As a result, major salivary changes in girls could most likely be due to this cause.

Overall findings have been reported that fasting has mostly caused changes in anthropometric parameters in girls and, as a result, antioxidant parameters have also been significantly modified in girls. Fasting, therefore, triggered major changes in the 
properties of antioxidants in a short-term fasting state. In the end, saliva can act as a good potent stress biomarker under stressful conditions.

\section{Conclusion}

During a different time interval, especially in children, the fasting condition affected anthropometric parameters (PR, SBP, and DBP). Salivary antioxidant activity was also reduced for fasting groups of children. Likewise, in fasting conditions, saliva may be a useful biomarker for oxidative stress. Research will be carried out with regard to the large population.

\section{Significant Statements}

- For the $1^{\text {st }}$ time, this study reports on salivary antioxidant properties after short-term exposure in boys and girls.

- $\quad$ The fasting condition affected anthropometric parameters (PR, SBP, and DBP) at different time intervals, especially in girls.

- The antioxidant properties in the fasting group were higher than in the control group of both sexes.

- $\quad$ Salivary antioxidant properties were mainly lower in fasting groups, both boys and girls. Fasting caused a reduction in the antioxidant properties of saliva.

- In fasting conditions, saliva can be a valuable biomarker for oxidative stress.

\section{Acknowledgments}

The authors are thankful to Vice-Chancellor of Arni University, Himachal Pradesh, India, for financial support. We are very grateful to all the dairy farmers for allowing and helping us during the sample collection. We are also thankful to Dr. Rajesh Kumar (HOD of Life Science Department) and Mrs. Indu Kumari (Research Associate, Life Science Department) for their continuous support during the entire laboratory work. We are grateful to all the volunteers who had willingly participated in this experiment.

\section{Conflicts of Interest}

All the authors are declaring that there are no any conflicts of interest related with this publication.

\section{References}

1. Paton DN. Essentials of Human Physiology. United Kingdom: Taylor \& Francis; 1905.

2. Ruhl S. The scientific exploration of saliva in the post-proteomic era: From database back to basic function. Expert Rev Proteomics 2012;9:85-96.

3. Greabu M, Battino M, Mohora M, Totan A, Didilescu A, Spinu T, et al. Saliva--a diagnostic window to the body, both in health and in disease. J Med Life 2009;2:124-32.

4. Wong DT. Salivary diagnostics powered by nanotechnologies, proteomics and genomics. J Am Dent Assoc 2006;137:313-21.

5. Schapher M, Wendler O, Gröschl M, Schäfer R, Iro H, Zenk J. Salivary leptin as a candidate diagnostic marker in salivary gland tumors. Clin Chem 2009;55:914-22.

6. Wu JY, Yi C, Chung HR, Wang DJ, Chang WC, Lee SY, et al. Potential biomarkers in saliva for oral squamous cell carcinoma. Oral Oncol 2010;46:226-31.

7. Zhang $\mathrm{T}$, Andrukhov $\mathrm{O}$, Haririan $\mathrm{H}$, Müller-Kern M, Liu S, Liu Z, et al.
Total antioxidant capacity and total oxidant status in saliva of periodontitis patients in relation to bacterial load. Front Cell Infect Microbiol 2016;5:97.

8. Sculley DV, Langley-Evans SC. Salivary antioxidants and periodontal disease status. Proc Nutr Soc 2002;61:137-43.

9. Adawi M, Watad A, Brown S, Aazza K, Aazza H, Zouhir M, et al. Ramadan fasting exerts immunomodulatory effects: Insights from a systematic review. Front Immunol 2017;8:1144.

10. Patterson RE, Sears DD. Metabolic effects of intermittent fasting. Ann Rev Nutr 2017;37:371-93.

11. Alsharidah AM, Murtaza G, Alsharidah MM, Bashir S. Fasting in Ramadan affects cognitive and physiological function in normal subjects (pilot study). Neurosci Med 2016;7:60-5.

12. de Toledo FW, Grundler F, Bergouignan A, Drinda S, Michalsen A. Safety, health improvement and well-being during a 4 to 21-day fasting period in an observational study including 1422 subjects. PLoS One 2019;14:e0209353.

13. Abe N, Nemoto A, Tsuchiya $Y$, Hojo H, Hirota A. Studies on the 1, 1-diphenyl-2-picrylhydrazyl radical scavenging mechanism for a 2-pyrone compound. Biosci Biotechnol Biochem 2000;64:306-13.

14. Benzie IF, Strain JJ. The ferric reducing ability of plasma (FRAP) as a measure of antioxidant power: The FRAP assay. Anal Biochem 1996;239:70-6.

15. El Ati J, Beji C, Danguir JA. Increased fat oxidation during Ramadan fasting in healthy women: An adaptative mechanism for body-weight maintenance. Am J Clin Nutr 1995;62:302-7.

16. Stockman MC, Thomas D, Burke J, Apovian CM. Intermittent fasting: Is the wait worth the weight? Curr Obes Rep 2018;7:172-85.

17. Longo VD, Mattson MP. Fasting: Molecular mechanisms and clinical applications. Cell Metab 2014;19:181-92.

18. Hall JE. Guyton and Hall Textbook of Medical Physiology. $13^{\text {th }}$ ed. Philadelphia, PA: Elsevier. 2016.

19. McAninch EA, Bianco AC. Thyroid hormone signaling in energy homeostasis and energy metabolism. Ann NY Acad Sci 2014;1311:77.

20. Berg JM, Tymoczko JL, Stryer L. Food intake and starvation induce metabolic changes. In: Biochemistry. $5^{\text {th }}$ ed. New York: W H Freeman; 2002.

21. Van Erp AC, Rebolledo RA, Hoeksma D, Jespersen NR, Ottens PJ, Nørregaard $R$, et al. Organ-specific responses during brain death: Increased aerobic metabolism in the liver and anaerobic metabolism with decreased perfusion in the kidneys. Sci Rep 2018;8:1-3.

22. Beauchaine TP, Hong J, Marsh P. Sex differences in autonomic correlates of conduct problems and aggression. J Am Acad Child Adolesc Psychiatry 2008;47:788-96.

23. Van De Wielle R, Michels N. Longitudinal associations of leptin and adiponectin with heart rate variability in children. Front Physiol 2017;8:498.

24. Bathina S, Das UN. Brain-derived neurotrophic factor and its clinical implications. Arch Med Sci 2015;11:1164.

25. Ramadan J, Telahoun G, Al-Zaid NS, Barac-Nieto M. Responses to exercise, fluid, and energy balances during Ramadan in sedentary and active males. Nutrition 1999;15:735-9.

26. Schull $Q$, Viblanc VA, Stier A, Saadaoui H, Lefol E, Criscuolo F, et al. The oxidative debt of fasting: Evidence for short-to mediumterm costs of advanced fasting in adult king penguins. J Exp Biol 2016;219:3284-93.

27. Weiss LR, Venezia AC, Smith JC. A single bout of hard RPE-based cycling exercise increases salivary alpha-amylase. Physiol Behav 2019;208:112555.

28. Tulunoglu Ö, Demirtas S, Tulunoglu I. Total antioxidant levels of saliva in children related to caries, age, and gender. Int J Paediatr Dent 2006;16:186-91.

29. Acquier AB, De Couto Pita AK, Busch L, Sánchez GA. Parameters of oxidative stress in saliva from patients with aggressive and chronic periodontitis. Redox Rep 2017;22:119-26.

30. Munther $\mathrm{S}$. The effects of cigarette smoking and exercise on total 
salivary antioxidant activity. Saudi Dent J 2019;31:31-8.

31. Greabu M, Didilescu A, Puiu L, Miricescu D, Totan A. Salivary antioxidant biomarkers in non-ferrous metals mine workers-a pilot study. J Oral Pathol Med 2012;41:490-3.

32. Gupta A, Kant S, Gupta SK, Prakash S, Kalaivani M, Pandav CS, et al.
Serum FRAP levels and pre-eclampsia among pregnant women in a rural community of Northern India. J Clin Diagn Res 2016;10:LC12.

33. Yadav AS, Saini M. Evaluation of systemic antioxidant level and oxidative stress in relation to lifestyle and disease progression in asthmatic patients. J Med Biochem 2016;35:55-62. 